\title{
CONTENT MARKETING DECISIONS FOR CUSTOMERS' DESIRED VALUE IN THE TOURISM SECTOR
}

\author{
Rūta Repovienė, Aušra Pažèraitė \\ Vytautas Magnus University, Lithuania \\ ruta.repoviene@vdu.lt
}

\begin{abstract}
In a landscape of increasing customer/firm interactions in digital space, content marketing, which aims to generate prospects and sales to foster customers' brand engagement, brand awareness and trust, is on the rise. Notwithstanding, despite significant marketing specialist interest, scientific content marketing research is not widely developed. Therefore, it encourages the need for new studies in the content marketing field.

This paper introduces theoretical and practical aspects of content marketing decisions for the creation of desired customer value in the tourism sector. The aim of the presented research is to determine which combinations of content marketing decisions could create the desired value for the customer in the tourism sector. Understanding the content marketing decisions that create the desired value for customers could lead to a proper implementation of content marketing in the tourism sector.

The presented results of q-sort study indicate twelve different combinations of content marketing decisions which could be used by tourism organizations in order to create desired value for their customer. Thus, it means that increasement of desired customer value can be made in the light of content marketing usage. The paper ends with insights, conclusions, limitations and future research possibilities.
\end{abstract}

Key words: content marketing, desired customers' value, tourism.

\section{Introduction}

Content marketing is a relatively new marketing concept which is focused on customers attraction and retention by creating and distributing relevant, unique, valuable, well produced and entertaining content. Need for this type of marketing emerged due to popularity of digital activities, information overload, increased competition, unconcerned internet users and willingness to attract and to keep customer interest on company or brand (Kidane \& Sharma, 2016; Kose \& Sert, 2017; Hollebeek \& Macky, 2019). As A. Karkar (2016) stated, companies that adapted content marketing perceive this is an effective technique in terms of guiding customers who are knowledgeable about the product and know how to choose the brand, and leading them to be loyal customers. Researchers (Kose \& Sert, 2017; Kaitosalmi, 2017; Bruhn \& Schnebelen, 2017) admit that content strategy is a view based on business strategy and customer insights, of what value to create for the customers, how to concretise the value in content, for whom to create it and in which channels to distribute it. Accordingly, there are several types of content marketing decisions in content creation stage: the idea of content decision, content distribution decision, content format decision and content element decision.

It is noticeable that content marketing concept is indirectly linked to the value for customer, which is always the goal of all companies (Danciu, 2016; Kumar \& Reinartz, 2016). For instance, content marketing and customer value are actualized by digitalization (Hollebeek \& Macky, 2019), and content marketing concept is based on valuable content (Jiao, Jo, \& Sarigöllü, 2017), thus content could be used as a value creation tool (Dvir, \& Gafni, 2018). Customer value is a construct which includes different value types related to different buying stages. Desired customer value is related to the purchase decision and possible actions before it. This type of value refers to what customer desire in a product or service (Shanker, 2012) is and is not limited to the direct benefits of the product. Furthermore, it reflects customer expectations and dominates in customer decision making process (McMurrian \& Matulich, 2016; Ntimane \& Tichaawa, 2017).

Accordingly, it is important to look for new decisions that could create desired customer value. A tourism sector is not an exception as the search for information online is an important part of the purchasing decision process ( $\mathrm{Wu}, 2018)$. However, despite the connection between customer value and content marketing, or supposed positive effect of this implementation, there is a lack of research in this particular field.

Considering the discussed connections, the object of this research is content marketing decisions directed towards the desired customer value in the tourism sector. The scientific problem solved by the research is formulated by the question: what type of content marketing decisions could create the desired value for customer in the tourism sector? Accordingly, the aim is to determine content marketing decisions that could create desired value for customer in the tourism sector.

\section{Materials and Methods}

Q-sort methodology was used to identify and classify marketing experts' viewpoint towards content marketing decisions for desired customer value creation in the tourism sector. Various researchers (Shinebourne, 2009; Zabala, 2014; Lobinger \& Brantner, 2015) describe a card sorting as a method by 
The sample of cards

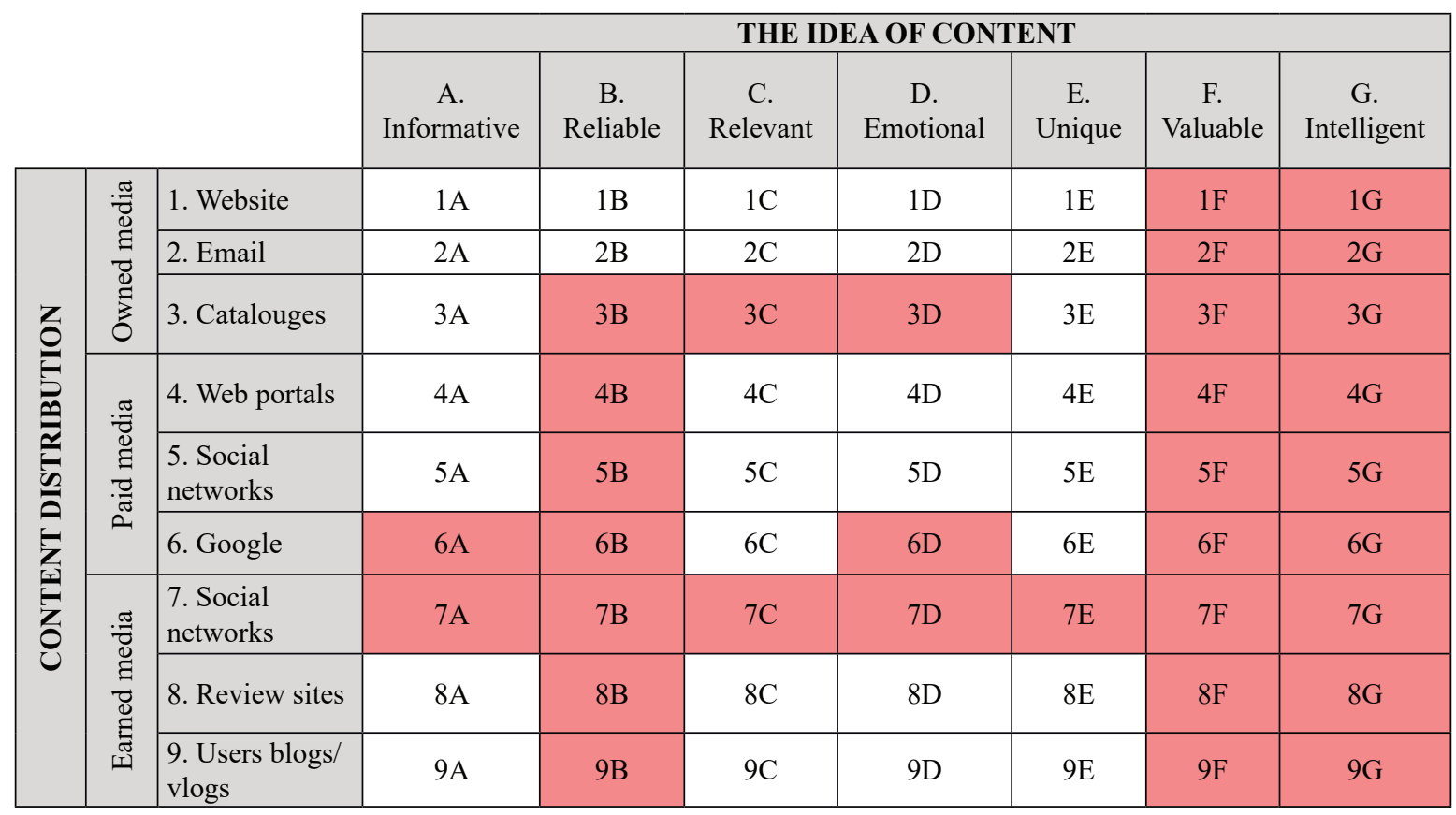

which it is possible to explore the different ways cards can be organized in particular categories. Application of the card sorting includes cards design, cards selection, method choice, participant determination, preparation of instructions, sorting process and given data analysis.

At the beginning, the authors prepared a sample of cards (Table 1) and selected cards for the next step of study. Two main types of content marketing decisions, the idea of content ( 5 ideas) and content distribution (9 channels), were chosen. Particular ideas were selected based on authors' previous research (Pažèraitė \& Repoviené, 2016). Due to the big amount of available channels for content marketing, particular 9 channels were chosen based on a structure of content marketing distribution, channel suitability for content marketing, channel usage in the tourism sector and channel popularity among customers.

This 63 cards collection was reduced to a final representative of 30 cards selection based on q-sort instructions (Shinebourne, 2009). Thus, illogical, duplicating or previously studied combinations were eliminated.

In the method choice stage, online card sorting platform from 'Optimal Workshop' was chosen. The main advantage is that sorting happens simultaneously and can be completely unmoderated. Besides that the chosen tool allows to provide instructions and guidelines for participants throughout the activity.

Based on the set aim and authors' ambitions to develop a foundation for further research involving a big number of consumers, 12 marketing experts from the tourism industry were selected to be first round respondents to provide data for this particular research. As it is marked in scientific literature (Shinebourne, 2009; Zabala, 2014), card sorting method requires a relatively small sample of respondents, especially in pilot researches. Participants were approached by e-mail, inviting them to online survey and providing detailed instructions for sorting.

During card sorting session, every participant was asked to sort 30 cards in random order over a

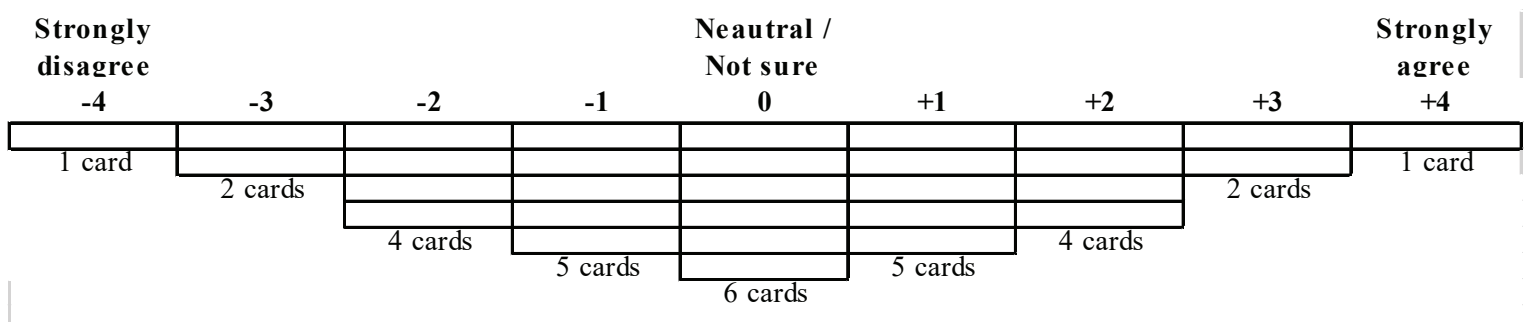

Figure 1. Card sorting grid. 
grid (Figure 1), from strong disagreement to strong agreement in a response to one question 'Which of these content marketing decisions could create a desired value for customers who are choosing services from tourism sector?'.

Results and insights were obtained through the analysis of card sorting arrangements. There are several ways to use card sorting method: problem/ insight identification, knowledge acquisition, participatory design activities, and evaluation/ optimization of a prototype. In this study, attention was given to knowledge acquisition and evaluation of particular content marketing decisions by analysing the physical distribution of sorted cards.

\section{Results and Discussion}

During the card sorting sessions, marketing experts from the tourism sector used all of the
30 combinations of content marketing decisions, distributing the cards across 9 different categories. The analysis of the research results starts with the review of popular card placements (Table 2). Popular placements matrix reveals the number of participants who sorted a particular card into the corresponding category. Furthermore, it attempts to propose the most popular groups based on each individual's highest placement score.

First of all, all negative categories should be reviewed. As shown in Table 2. 6 different cards were assigned to the category 'Strongly disagree (-4)' which has 1 card limit. Despite that, this category has one leading card which was selected by five participants (6E: Unique content in Google search platform). This category also contained several cards covering emotional content (in total 4 times) and content sent by email (in total 4 times). To the category 'Disagree

\section{Popular placements matrix}

Table 2

\begin{tabular}{|c|c|c|c|c|c|c|c|c|c|c|c|}
\hline & -4 & -3 & -2 & -1 & $\mathbf{0}$ & +1 & +2 & +3 & +4 & $\begin{array}{c}\text { CATEGORIES } \\
\text { PER CARD }\end{array}$ & $\sigma$ \\
\hline 6E. & 5 & 5 & 2 & & & & & & & 3 & 0.8 \\
\hline $2 D$. & 3 & 4 & 4 & 1 & & & & & & 4 & 1.0 \\
\hline 4D. & 1 & 5 & 3 & 3 & & & & & & 4 & 1.0 \\
\hline $1 \mathrm{~B}$. & & 3 & 5 & 3 & & 1 & & & & 4 & 1.1 \\
\hline $2 B$. & 1 & & 6 & 3 & 1 & 1 & & & & 5 & 1.2 \\
\hline 6C. & & & 6 & 4 & 1 & 1 & & & & 4 & 1.0 \\
\hline 5A. & 1 & & 3 & 6 & 1 & & 1 & & & 5 & 1.4 \\
\hline 8D. & & 1 & 3 & 7 & 1 & & & & & 4 & 0.8 \\
\hline 9E. & & 1 & 2 & 7 & 1 & 1 & & & & 5 & 1.0 \\
\hline 8E. & & 2 & 3 & 3 & 3 & & 1 & & & 5 & 1.4 \\
\hline 3A. & 1 & & 3 & 4 & 3 & 1 & & & & 5 & 1.3 \\
\hline 2E. & & & 1 & 4 & 4 & 3 & & & & 4 & 1.0 \\
\hline $1 D$. & & & 1 & 4 & 5 & 2 & & & & 4 & 0.9 \\
\hline 4A. & & 1 & 3 & 1 & 5 & 2 & & & & 5 & 1.3 \\
\hline 9D. & & 1 & 1 & 4 & 6 & & & & & 4 & 1.0 \\
\hline 3E. & & & 1 & 2 & 6 & 2 & 1 & & & 5 & 1.0 \\
\hline 4E. & & 1 & & 2 & 6 & 3 & & & & 4 & 1.1 \\
\hline 9A. & & & & & 7 & 3 & 2 & & & 3 & 0.8 \\
\hline 5D. & & & & & 5 & 5 & 1 & 1 & & 4 & 0.9 \\
\hline 1E. & & & & & 4 & 6 & 1 & & 1 & 4 & 1.1 \\
\hline 4C. & & & & & & 8 & 3 & 1 & & 3 & 0.7 \\
\hline $2 \mathrm{~A}$. & & & & 2 & 2 & 4 & 3 & 1 & & 5 & 1.2 \\
\hline 9C. & & & & & 4 & 4 & 2 & 1 & 1 & 5 & 1.3 \\
\hline $8 C$. & & & & & 2 & 3 & 5 & 2 & & 4 & 1.0 \\
\hline 8A. & & & & & 1 & 3 & 4 & 2 & 2 & 5 & 1.2 \\
\hline $1 \mathrm{~A}$. & & & & & & 1 & 6 & 3 & 2 & 4 & 0.9 \\
\hline 1C. & & & & & 1 & 1 & 5 & 3 & 2 & 5 & 1.2 \\
\hline $2 C$. & & & & & 2 & 1 & 6 & 3 & & 4 & 1.0 \\
\hline 5E. & & & 1 & & 1 & 2 & 4 & 4 & & 5 & 1.5 \\
\hline $5 \mathrm{C}$. & & & & & & 2 & 3 & 3 & 4 & 4 & 1.1 \\
\hline CARDS PER CATEGORY & 6 & 10 & 17 & 17 & 23 & 23 & 16 & 11 & 6 & & \\
\hline
\end{tabular}


$(-3)$ ' 10 different cards were assigned and 2 cards dominate (each assigned 5 times): 4D (Emotional content published in web portals) and $6 \mathrm{E}$, which was the most popular card in category 'Strongly disagree $(-4)$ ', too. It could also be observed that category 'Disagree (-3)' often comes along with other cards that include emotional content (in total selected 11 times), content published in web portals (in total selected 7 times) and content published in review sites (in total selected 3 times). More than half - 17different cards were allocated to the category 'Partly disagree (-2)', which hold 4 card positions. 6C (Relevant content in Google search platform) and 2B (Reliable content sent by email) were most frequently designated as a combination of content marketing decisions that are partly unable to create desired value for customers. Despite the wide distribution of cards and its variety, different content marketing decisions that include emotional content (emotional content in web portals; emotional content sent by email; emotional content on review pages; emotional content in other users' blogs/ vlogs; emotional content on website) were sorted into 'Partly disagree (-2)' category 12 times (half of all selections in this category). Category 'More disagree, than agree (-1)' has a 5 cards limit and collected 17 different cards in total, the same as category 'Partly disagree (-2)'. This category was mostly attributed to two types of cards: 8D (Emotional content on review sites) and 9E (Unique content in other users' blogs/ vlogs).

However, the review of negative categories shows that there are only 3 different cards which were not assigned to any positive category and 2 different cards whose highest placement was in the category 'Neutral / Not sure (0)': 6E, 2D (Emotional content sent by email), 4D, 8D and 9D (Emotional content in other users' blogs/vlogs).

Analysis of category 'Neutral / Not sure (0)', which holds 6 cards positions, revealed that even 23 different cards were associated with a particular category. It could be explained by the fact that this category is the most widespread and the most acceptable for tourism marketing experts who are hesitant about a specific combination of content marketing decisions. 9A (Informative content in other users' blogs/vlogs) was the most common in this category. Because of the fact that this category collected more than two-thirds of the entire card pile, there are a few cards which were selected by 6 respondents each: 9D, 3E (Unique content in tourism catalogues) and 4E (Unique content published in web portals).

Reviewing the positive categories shows that the first category 'More agree than disagree $(+1)$ ' attracts as many cards as the neutral category (in total 23 cards) and 6 cards more than the category 'More disagree than agree $(-1)$ '. It means that tourism marketing experts appreciate the potential of content marketing decisions for the creation of desired customer value more positively than negatively. In addition, this category was attributed to a card that was the most frequently rated (selected 8 by participants): 4C (Relevant content published in web portals). 1E (Unique content on a website) was assigned into this category by half of participants, as well. As presented, popular placement matrix (Table 2) shows that 16 different cards were assigned to the category 'Partly agree (+2)' which has 4 card limit - fewer card spread as in the category 'Partly disagree (-2)'. Accordingly, the category 'Partly agree $(+2)$ " has two leading cards (as well as category 'Partly disagree (-2)'), which was selected by 6 participants each (1A (Informative content on website) and 2C (Relevant content sent by email)). This category also came with several cards covering relevant content (in total 22 times), content published on a company website (in total 12 times), content in review sites (in total 9 times) and content in social networks (in total 8 times). In the category 'Agree (+3)', it appears that it has collected one card more (in total 11 cards) than analogous category on the negative side of the card sorting grid. 5E (Unique content in social networks) was most frequently designated as a combination of content marketing decisions, which are able to create desired value for customers. Considering the wide distribution of cards, 6 from 7 different content marketing decisions, which include relevant content (relevant content in social networks; relevant content on review sites; relevant content sent by email; relevant content on website; relevant content published in web portals; relevant content in other users' blogs/vlogs), were sorted into 'Agree (+3)' category 13 times (more than half of all selections in this category). Category 'Strongly agree $(+4)$ ' has 1 card limit and collected 6 different cards in total, the same as the category 'Strongly disagree (-4)'. Category 'Strongly agree $(+4)$ ' was mostly attributed to one type of card: $5 \mathrm{C}$ (Relevant content in social networks) and came with a few cards covering the content on a website (in total 5 times and informative content (in total 4 times).

Finally, by completing the review of card placements, it could be noted that there are 11 different cards which were not assigned to any negative category: 9A, 5D (Emotional content on social networks), 1E, 4C, 9C (Relevant content in other users' blogs/vlogs), 8C (Relevant content on review websites), 8A (Informative content on review websites), 1A, 1C (Relevant content on a website), 2C and $5 \mathrm{C}$. Analysis reveals that a much larger part of the content marketing solutions is considered to constitute a positive value for the consumers in the tourism services sector. Therefore, the analysis of card display results also showed that a much bigger proportion of 
content marketing decisions (i.e. different types of cards) were considered to be positive than negative in order to create the desired customer value in the tourism sector.

When assessing the distribution of individual card in different categories, it was revealed that all cards spread between 3 and 5 categories per card (in total 9 categories). Consequently, the average is 4.3 positions per card. This means that a single card evaluation made by a separate marketing expert is partly different and might vary across evaluation scales. Accordingly, only three cards were limited by three categories: 6E, 9A, 4C.

Although the card sorting method includes many attributes from qualitative research, it is worth to take a look at the trends in the deviation of values in order to understand the level of homogeneity of participants evaluation. Deviation of the larger part of the cards does not exceed more than one category position, so a common attitude between the different participants can be noticed. The biggest diversion between separate card evaluation is in $5 \mathrm{E}$ case $(\sigma=1.5)$. 8E (Unique content in review sites), and $5 \mathrm{~A}$ (Informative content in social networks) was also assessed differently $(\sigma=1.4)$. On the other hand, analysis of the deviation showed that $4 \mathrm{C}(\sigma=0.7), 6 \mathrm{E}(\sigma=0.7)$ and $8 \mathrm{D}(\sigma=0.7)$ have the most homogeneous assessments.

Focusing on individual content marketing decisions, it can be seen that the number of data variation is different as well. Participants' opinions were more diverged on 'content in social networks' and 'informative content' cards. In contrast, possibilities of 'content in Google platform' and 'emotional content' to create desired value for customers in the tourism sector were assessed in a quite similar way.

The analysis of the research results continues with the review of card arrangements (Figure 2). In order to determine, which combinations of content marketing decisions create desired value for customers in the tourism sector and which do not, the focus was on average (AM) and the most often value (Mode) of individual card evaluation.

As one may see (Figure 2), the range of card evaluation varies between -3.3 and +2.8 . This means that none card, in the overall result, reaches a total agreement $(+4)$ or total disagreement (-4) from marketing experts who work in the tourism sector. The most unfavourable combination of content marketing decision is $6 \mathrm{E}(\mathrm{AM}=-3.3 ;$ Mode=-4).
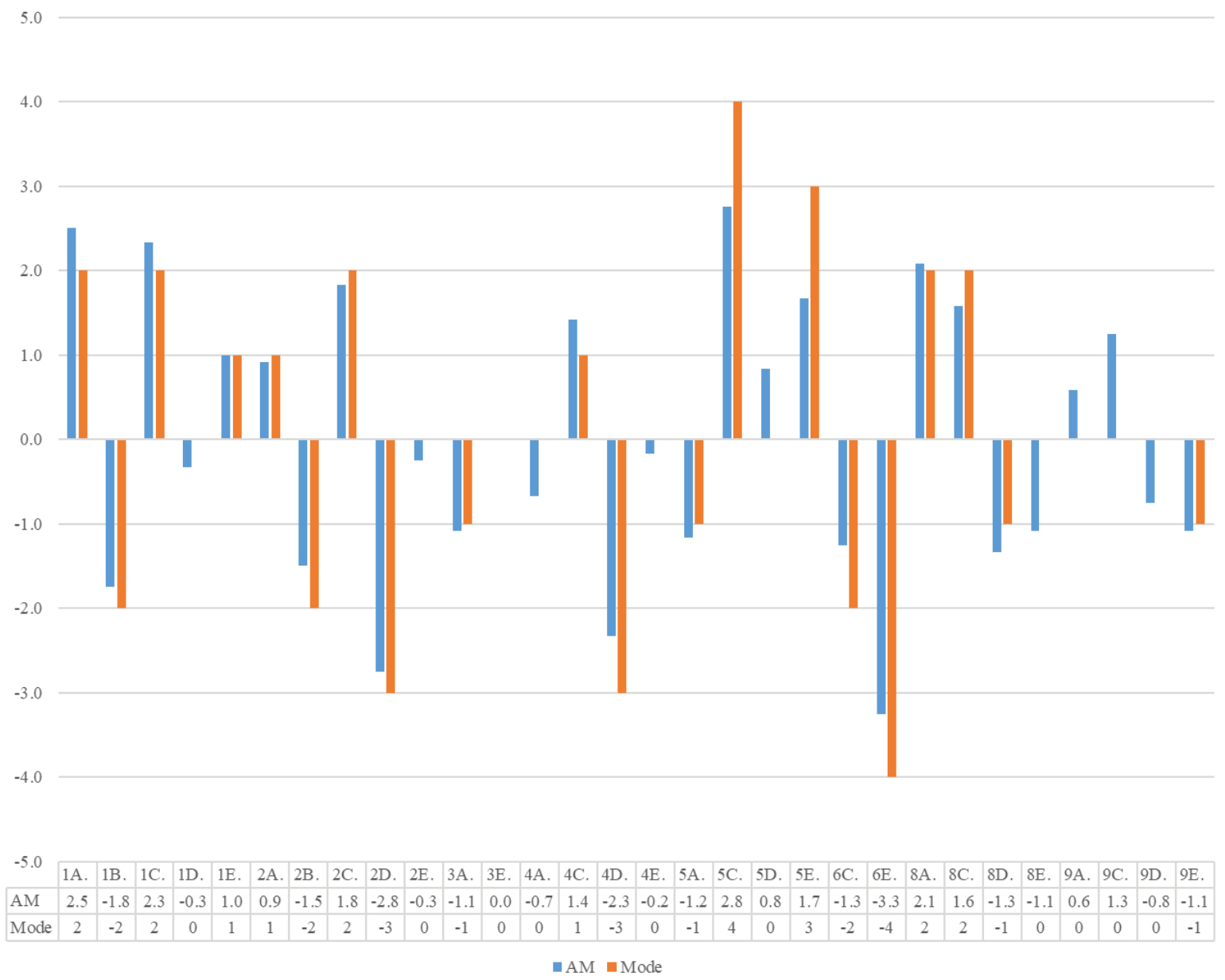

Figure 2. Card arrangements. 


\begin{tabular}{|c|c|c|c|c|c|c|c|c|}
\hline \multicolumn{2}{|c|}{$\begin{array}{c}\text { Does not create } \\
\text { desired customers' } \\
\text { value }\end{array}$} & \multicolumn{5}{|c|}{ Neautral } & \multicolumn{2}{|c|}{$\begin{array}{l}\text { Create desired } \\
\text { cutomers' value }\end{array}$} \\
\hline \multirow[t]{6}{*}{$6 \mathrm{E}$} & $4 \mathrm{D}$ & $6 \mathrm{C}$ & 9D & $9 \mathrm{~A}$ & $4 \mathrm{C}$ & $8 \mathrm{~A}$ & $1 \mathrm{~A}$ & $5 \mathrm{C}$ \\
\hline & $2 \mathrm{D}$ & $8 \mathrm{D}$ & $9 \mathrm{E}$ & $3 \mathrm{E}$ & $9 \mathrm{C}$ & $2 \mathrm{C}$ & $1 \mathrm{C}$ & \\
\hline & & $2 B$ & $8 \mathrm{E}$ & $4 \mathrm{E}$ & $1 \mathrm{E}$ & $5 \mathrm{E}$ & & \\
\hline & & $1 \mathrm{~B}$ & $3 \mathrm{~A}$ & $2 \mathrm{E}$ & $2 \mathrm{~A}$ & $8 \mathrm{C}$ & & \\
\hline & & & $5 \mathrm{~A}$ & $1 \mathrm{D}$ & $5 \mathrm{D}$ & & & \\
\hline & & & & $4 \mathrm{~A}$ & & & & \\
\hline
\end{tabular}

Figure 3. Combinations of content marketing decision for desired customer value in the tourism sector.

Other unfavourable ( -2 and less) cards appeared in the following order: $2 \mathrm{D}(\mathrm{AM}=-2.8 ; \mathrm{Mode}=-3)$ and $4 \mathrm{D}$ $(\mathrm{AM}=-2.3$; Mode $=-3)$.

Hence, only 3 combinations of content marketing decisions (two of them include emotional content) are seen as really incapable of creating desired value for the consumer. The most disliked content marketing decisions are reliable content $(\mathrm{AM}=-1.63)$ and content in Google platform $(\mathrm{AM}=-2.3)$. Results of 4 cards show these cards as the most neutral (AM is between -0.5 and +0.5 ) combinations of content marketing decisions in a perspective of desired customer value creation: $3 \mathrm{E}(\mathrm{AM}=0.0 ; \mathrm{Mode}=0)$, 4E $(\mathrm{AM}=-0.2 ;$ Mode=0), 2E (Unique content sent by email $(\mathrm{AM}=-0.3$; Mode $=0)$ ) and $1 \mathrm{D}$ (Emotional content on website $(\mathrm{AM}=-0.3$; Mode $=-0)$ ). As it can be seen, three-quarters of these cards are related to content uniqueness. The most favourable combination of content marketing decision is $5 \mathrm{C}(\mathrm{AM}=+2.8$; Mode=4). Next favourable ( +2 and more) cards ranked as follows: 1A (AM=+2.5; Mode=2), $1 \mathrm{C}$ $(\mathrm{AM}=+2.3$; Mode=2) and 8A $(\mathrm{AM}=+2.1$; Mode=2). The most favourite content marketing decisions are relevant to content $(\mathrm{AM}=1.43)$ and content in social networks $(\mathrm{AM}=1)$. Accordingly, combinations of content marketing decisions have more possibilities to create desired value for a customer.

Despite that the most unfavourable combinations (6E, 2D, 4D) get stronger disagreement (average AM= -2.8 , Mode $=-3$ ) than the most favourable combinations $(5 \mathrm{C}, 1 \mathrm{~A}, 1 \mathrm{C}, 8 \mathrm{~A})$ gets an agreement (average $\mathrm{AM}=$ +2.4 . average Mode=2). However, it can be noticed that the difference between AM values of 4 favourable cards is less (AM from +2.1 to +2.8 ) than between the values of 3 the most unfavourable cards (from -3.3 to -2.3 ). Thus, the research participants are more likely to appreciate the equal potential of favourite combinations.

Finally, corresponding to the aim of the study, content marketing decisions, which create desired customer value, can be determined. It can be seen in the figure above (Figure 3), that if a tourism organisation wants to create more desired value for a customer, it should use one of following combinations of content marketing decisions: relevant, unique or emotional content in social networks (paid media); informative, unique or relevant content on organization website (owned media); informative or relevant content on review sites (earned media); relevant or informative content sent by email (owned media); relevant content published on web portals (paid media); and relevant content in other users' blogs/vlogs (earned media).

Importance of unique content, which is relevant for a user and gives him or her a desired information about the possible benefits, is revealed. Thus, it is clear that marketing experts and content marketing theorists (Karkar, 2016; Pažèraitė \& Repovienè, 2016; Kaitosalmi, 2017) have the same understanding about what the content should be. Interpretations of the results provide some insights as well. It is noticeable that reliability, one of the most important attributes of content marketing (Pažèraitè \& Repovienè, 2016), was not so favourably assessed as a part of particular combinations. Perhaps this could be explained by the fact that all content published by an organisation should be reliable, and it is more a necessity than an opportunity, sspecially so, when it comes to the desired customer value, which is associated with consumer's expectations and all risks related to it. We see that even emotional content is not the most suggestive for the organisation seeking to create desired customer value. Its ability to create desired value depends on a distribution channel and its suitability for such content.

From a content distribution perspective, various distribution channels can be used for the creation of desired customer value in the tourism sector and there is not one leading distribution decision. It is worth paying attention to several of the following ones: to owned, paid and earned media. According to the results, the Google search platform is only one content distribution channel, which is strictly not recommended for the creation of the desired customer value. It can be explained by the nature of this platform - it is a shortstop for the customer between a search performed and a website, i.e. main content location. Social networks, the most favourable distribution channel according to the research results, provide opportunities not only for various types of 
content marketing decisions but for various initiatives as well. It can be used in a range from simple boosting to collaboration with influencers or user-generated content decisions. Searching for new ways to create and distribute content in tourism review sites and other users' blogs/vlogs is worth paying attention as well. Content marketing decisions in tourism catalogues, email and web portals were treated differently. Therefore, their usage or not usage for the desired value creation should be determined by the idea of the content. At the end, no tourism organisation shoul forget the importance of their websites.

Taking into account the research results, it could be stated that there are several combinations of content marketing decisions that could be used for desired customer value creation in the tourism sector. These combinations can help to attract customers' attention, educate them and reveal all values that could be obtained by choosing a particular tourism product or services. All this leads to a growing desired customer value and possible value from the customers.

\section{Conclusions}

1. This study provides novel insights into the possible interconnections among content marketing, new marketing paradigm and customer value, as the main goal of all companies. Therefore, the application of content marketing decisions in the tourism sector for creation of desired customer value, which dominate in customer decision making process, can provide positive results for companies and require a deeper examination.

2. Conducted q-sort research contributes to the knowledge advancement in the marketing theory and the tourism industry. The results obtained in the current study show that there are twelve different combinations of content marketing decisions which can create desired value for customers. The main focus of a company, which would like to adopt content marketing for customer value creation, should be dedicated to relevant, informative and unique content distributed in social networks, company website or review sites.

3. The present study is the first step of continuing research in developing proper content marketing decisions for improved customers' perceived value. The study could be continued in various ways: with expanded research sample, expanded number of decisions to be tested, selection of another sector, selection of other customer value types or obtaining results by applying other qualitative and quantitative research methods.

\section{References}

1. Bruhn, M., \& Schnebelen, S. (2017). Integrated marketing communication-from an instrumental to a customer-centric perspective. European Journal of Marketing, 51(3), 464-489. DOI: 10.1108/EJM-082015-0591.

2. Danciu, V. (2016). The potential of shared value creation: a theoretical analysis. Romanian Economic Journal, 60 (19), 3360. Retrieved February 24, 2019, from http://www.rejournal.eu/sites/rejournal. versatech.ro/files/articole/2016-06-15/3366/3danciu.pdf.

3. Dvir, N., \& Gafni, R. (2018). How Content Volume on Landing Pages Influences Consumer Behavior. In Informing Science and Information Technology Education Conference, 23-28 June (35-53). Santa Rosa, CA: Informing Science Institute. DOI: 10.28945/4016.

4. Hollebeek, L.D., \& Macky, K. (2019). Digital Content Marketing's Role in Fostering Consumer Engagement, Trust, and Value: Framework, Fundamental Propositions, and Implications. Journal of Interactive Marketing, 45. 27-41. DOI: 10.1016/j.intmar.2018.07.003.

5. Jiao, Y., Jo, M.S., \& Sarigöllü, E. (2017). Social Value and Content Value in Social Media: Two Paths to Psychological Well-Being. Journal of Organizational Computing and Electronic Commerce, 27(1), 3-24. DOI: 10.1080/10919392.2016.1264762.

6. Kaitosalmi, S. (2017). The creation of a content marketing plan for a new start-up in the financial sector. Retrieved March 1, 2019, from https://www.theseus.fi/handle/10024/132523.

7. Karkar, A. (2016). Content marketing on the increase of value and confidence network. International Journal of Social Sciences and Education Research, 2 (1), 334-348. Retrieved February 25, 2019, from http://dergipark.gov.tr/download/article-file/389583.

8. Kidane, T.T., \& Sharma, R.R.K. (2016). Factors affecting consumers' purchasing decision through e-commerce. Retrieved February 20, 2019, from http://ieomsociety.org/ieom_2016/pdfs/52.pdf.

9. Kose, U., \& Sert, S. (2017). Improving content marketing processes with the approaches by artificial intelligence. Eforum, 6(1), 18. Retrieved February 22, 2019, from https://arxiv.org/ftp/arxiv/ papers/1704/1704.02114.pdf.

10. Kumar, V., \& Reinartz, W. (2016). Creating enduring the customer value. Journal of Marketing, 80 (6), 36-68. DOI: 10.1509/jm.15.0414. 
11. Lobinger, K., \& Brantner, C. (2015). Likable, funny or ridiculous? A Q-sort study on audience perceptions of visual portrayals of politicians. Visual Communication, 14(1), 15-40. DOI: 10.1177/1470357214554888.

12. McMurrian, R.C., \& Matulich, E. (2006). Building the customer value and profitability with business ethics. Journal of Business \& Economics Research, 4(11), 11-18. Retrieved January 26, 2019, from https:// www.researchgate.net/profile/Robert_Mcmurrian/publication/255610639_Building_The customer_ Value_And_Profitability_With_Business_Ethics/links/540deffb0cf2d8daaacd3974.pdf.

13. Ntimane, V., \& Tichaawa, T.M. (2017). Customers' Perceptions of Value in Relation to Hotels in Gauteng South Africa. Economica, 13 (2), 1730. Retrieved January 26, 2019, from https:/www.ceeol.com/search/ article-detail id $=546804$.

14. Pažèraitè, A., \& Repovienè, R. (2016). Content marketing elements influence on search advertisement effectiveness: theoretical background and practical insights. Management of Organizations: Systematic Research, 75, 97-109. DOI: 10.7220/MOST.2335.8750.2016.75.7.

15. Shanker, A. (2012). What is customer value and how do you deliver it? Technology Innovation Management Review, 2 (2), 32-33. Retrieved February 24, 2019, from http://timreview.ca/article/525.

16. Shinebourne, P. (2009). Using Q method in qualitative research. International Journal of Qualitative Methods, 8 (1), 93-97. DOI: 10.1177/160940690900800109.

17. Wu, G. (2018). Official websites as a tourism marketing medium: A contrastive analysis from the perspective of appraisal theory. Journal of Destination Marketing \& Management, 10, 164-171. DOI: 10.1016/j.jdmm.2018.09.004.

18. Zabala, A. (2014). Qmethod: a package to explore human perspectives using Q methodology. $R$ Journal, 6 (2), Retrieved February 22, 2019, from http://journal.r-project.org/archive/2014-2/zabala.pdf. 